\title{
PENTINGNYA SUPERVISI UNTUK PENGEMBANGAN STAFF DI MADRASYAH IBTIDAIYAH MUHAMMADIYYAH JUWIRAN KLATEN
}

\author{
Meti Fatimah $^{1}$, Ainun Mardhiyah², Ismi Nur Azizah ${ }^{3}$ \\ ${ }^{123}$ Fakultas Tarbiyah Institut Islam Mamba'ul 'Ulum Surakarta \\ e-mail: fatimahcan@gmail.com
}

\begin{abstract}
The purpose of this study was to determine the importance of supervision of staff development at Madrasyah Ibtidayyah Muhammadiyah Juwiran Klaten. The type of research used is descriptive qualitative. With the method of collecting data through observation, interviews and documentation. While the data analysis activities are data reduction, data presentation, and drawing conclusions. The results of this study indicate that one way to develop human resources at Madrasyah Ibtidaiyyah Muhammadiyah Juwiran Klaten is by supervision, by improving the quality of education which must start from the aspect of teachers and other education personnel concerning the quality of their professionalism and welfare in a professional education management.
\end{abstract}

Keywords: importance of supervision, staff development, madrasyah

\section{PENDAHULUAN}

Seiring dengan tantangan pendidikan yang semakin komplek dan kebijakan mutu yang di keluarkan oleh pemerintah, maka para guru dan tenaga kependidikan yang ada di lingkugan pendidikan harus mampu mengembangkan kemampuan dan potensi diri yang dapat menunjang kinerja dan meringankan tugas profesi. Sumber daya manusia disuatu lembaga pendidikan merupakan faktor yang sangat berperan dalam mewujudkan pendidikan yang bermutu. ${ }^{1}$ Sebagai mana kita ketahui bahwa kualitas atau mutu sebuah lembaga dapat di ukur dari proses pelayanan dan kemampuan lembaga pendidikan untuk men-sinergikan seluruh potensi yang ada sehingga tercipta sebuah keunggulan yang menjadi trade mark dari sebuah lembaga pendidikan tersebut. Semakin guru itu bekerja dengan penuh antusias, bermotivasi, dinamis mengikuti kemajuan baik teori, instrumen, teknologi maupun kebijakan pemerintah, maka akan semakin tinggi produktifitas sekolah. ${ }^{2}$

Salah satu poin yang sangat menentukan dalam pemberian layanan dalam sebuah lembaga pendidikan adalah kualitas pemberi layanan yaitu sumber daya manusia yang langsung bersentuhan dengan pengguna layanan pendidikan. Sumber daya manusia dianggap semakin penting peranannya dalam pencapaian tujuan, maka berbagai pengalaman dan hasil penelitian dalam bidang sumber daya manusia dikumpulkan secara sisitematis dalam apa yang disebut dengan manajemen sumber daya manusia. ${ }^{3}$ Guru merupakan suatu profesi yang

\footnotetext{
${ }^{1}$ Lukman Nasution, Saiful Sagala; dan Eka Daryanto. "Kebijakan Kepala Sekolah Sebagai Supervisor dalam Pengembangan Staf dan Kurikulum di SMA Negeri 2 Medan". Educandu M: Jurnal Manajemen Pendidikan, Vol.11 No.2 2018, Pp 1.

${ }^{2}$ Muh. Fitrah, "Peran Kepala Sekolah dalam Meningkatkan Mutu Pendidikan", Jurnal Penjaminan Mutu, Vol. 3 No 1 2017, Pp 34. DOI: http://dx.doi.org/10.25078/jpm.v3i1.90

${ }^{3}$ M. Nazar Almasri, "Manajemen Sumber Daya Manusia: Imlementasi dalam Pendidikan Islam", Kutubkhanah: Jurnal Penelitian Sosial Keagamaan, Vol.19, No.2 2016, Pp. 134.
} 
berarti suatu jabatan yang memerlukan keahlian khusus sebagai guru dan tidak dapat dilakukan oleh sembarang orang diluar bidang pendidikan. Di samping dengan keahliannya, sosok profesional guru ditunjukkan melalui tanggung jawabnya dalam melaksanakan seluruh pengabdiannya, profesional hendaknya mampu memikul dan melaksanakan tanggung jawab sebagai guru kepada peserta didik, orang tua, masyarakat, bangsa negara dan agarnanya. Guru profesional mempunyai tanggung jawab sosial, intelektual, moral dan spiritual. ${ }^{4}$

Di dalam mengembangkan proses belajar mengajar, seorang supervisor berperan aktif. Supervisor memegang peranan penting dalam meningkatkan kualitas guru agar dapat melaksanakan pembelajaran yang lebih berkualitas karena, jabatan supervisor di sekolah meliputi kepala sekolah dan pengawas. ${ }^{5}$ Yang mana seorang supervisor harus dapat melihat potensi dari sumberdaya staf pendidik/guru, setelah itu hendaknya seorang supervisor dapat membina dan mengembangkan potensi yang dimiliki oleh seorang guru didalam melaksanakan proses belajar mengajar. Dan di dalam melaksanakan tugasnya, seorang guru akan mengahadapi problem-problem yang mungkin dia sendiri tidak dapat memecahkannya. Dari sekian problem yang ada pada para pendidik adalah bahwa sebagian besar orang yang menyandang profesi guru hanyalah sebatas profesi belum terpatri dalam jiwanya sebagai pendidik, juga sebagian besar para pendidik belum berperan sebagai pendidik yang sesungguhnya tapi hanya sekedar sebagai pentransfer ilmu pengetahuan. ${ }^{6}$

Dari sinilah pentingnya peran supervisi dalam menyelesaikan permasalahan yang ada pada seorang guru, masalah tersebut harus mendapat perhatian serius dari seorang supervisor dalam hal ini kepala sekolah untuk memberikan bantuan kepada guru dalam menghadapi masalah yang dihadapi terkait dengan kualitas diri dan kemampuan dalam pembelajaran.

\section{METODE PENELITIAN}

Penelitian ini merupakan jenis penelitian kualitatif. Penelitian kulitatif ini merupakan penelitian yang jenis datanya bersifat non angka bisa berupa kalimat, pernyataan, dokumen serta data lain yang bersifat memberikan deskripsi dan kategorisasi berdasarkan kancah penelitian. ${ }^{7}$ Penelitian ini menggunakan metode wawancara, metode observasi dan dokumentasi dalam mengumpulkan data. Sedangkan teknik analisis data yang digunakan dalam penelitian ini yaitu mereduksi data, menyajikan data, serta yang terakhir adalah penarikan kesimpulan.

\section{PEMBAHASAN}

\section{Pengertian Supervisi}

Kata supervisi berasal dari bahasa Inggris "supervision" yang terdiri dari dua kata "super" dan "vision". Super berarti atas atau lebih, sedangkan vision berarti melihat atau meninjau. Secara etimologis supervisi berarti melihat atau meninjau dari atas atau menilik dan menilai dari atas yang dilakukan oleh pihak atasan terhadap perwujudan kegiatan dan

\footnotetext{
${ }^{4}$ Abdul Hamid, "Guru Profesional", Al Falah: Jurnal Ilmiah Keislaman dan Kemasyarakatan, Vol. XVII No. 32, 2017, Pp. 278. DOI: https://doi.org/10.47732/alfalahjikk.v17i2.26

${ }^{5}$ Ahmad Sabandi, "Supervisi Pendidikan Untuk Pengembangan Profesionalitas Guru Berkelanjutan", Pedagogi: Jurnal Ilmiah Ilmu Pendidikan, Vol. Xiii No.2, 2013, Pp. 2.

${ }^{6}$ Amrullah Aziz, "Pendidik Profesional yang Berjiwa Islami", Pancawahana: Jurnal Studi Islam, Vol. 10, No. 12015 , Pp. 57.

${ }^{7}$ Musfiqon. 2015. Panduan Lengkap Metodologi Penelitian Pendidikan. Jakarta: PT. Prestasi Pustakaraya, hlm. 70 .
} 
hasil kerja bawahan. ${ }^{8}$ Kepala sekolah sebagai pemimpin pendidikan di sekolah merupakan actor kunci dalam memberdayakan segenap sumber daya yang ada di sekolah. ${ }^{9}$ Supervisi di sekolah dilaksanakan oleh kepala sekolah yang bertindak sebagai supervisor, maka ia harus mampu melakukan berbagai pengawasan dan pengendalian untuk meningkatkan kinerja guru. ${ }^{10}$

Supervisi mempunyai pengertian yang luas. Supervisi adalah segala bantuan dari para pemimpin sekolah, yang tertuju kepada perkembangan kepemimpinan guru-guru dan personel sekolah lainnya didalam mencapai tujuan-tujuan pendidikan. Guru merupakan orang sangat berperan dalam pencapaian tujuan pendidikan di sekolah, karena guru adalah orang yang merencanakan, melaksanakan dan mengevaluasi hasil belajar siswa. ${ }^{11}$ Supervisi berupa dorongan, bimbingan dan kesempatan bagi pertumbuhan keahlian dan kecakapan guru-guru, seperti bimbingan dalam usaha dan pelaksanaan pembaharuanpembaharuan dalam pendidikan dan pengajaran, pemilihan alat-alat pelajaran dan metode-metode mengajar yang lebih baik, cara-cara penilaian yang sistematis terhadap fase seluruh proses pengajaran, dan sebagainya. Dengan kata lain "Supervisi ialah suatu aktifitas pembinaan yang direncanakan untuk membantu para guru dan pegawai para sekolah lainnya dalam melakukan pekerjaan mereka secara efektif'.

Fungsi pengawasan atau supervisi dalam pendidikan bukan hanya sekadar kontrol melihat apakah segala kegiatan telah dilaksanakan sesuai dengan rencana atau program yang telah digariskan, tetapi lebih dari itu. Supervisi dalam pendidikan mengandung pengertian yang luas. Kegiatan supervisi mencakup penentuan kondisi-kondisi atau syarat-syarat personel maupun material yang diperlukan untuk terciptanya situasi belajar mengajar yang efektif, dan usaha memenuhi syarat-syarat itu. Pengawasan dan pengendalian merupakan tindakan preventiv untuk mencegah agar guru tidak melakukan penyimpangan dan lebih berhatihati dalam melaksanakan pekerjaannya sebagai pendidik. ${ }^{12}$

Tujuan supervisi ialah memperkembangkan situasi belajar dan mengajar yang lebih baik. Usaha kearah perbaikan belajar dan mengajar ditujukan kepada pencapaian tujuan akhir dari pendidikan yaitu pembentukan pribadi anak secara maksimal. ${ }^{13}$ Adapun fungsi utama dari supervisi pendidikan seperti yang dikemukakan oleh Sahertian, bahwa fungsi dasar dari supervisi adalah untuk memperbaiki situasi belajar mengajar di sekolah agar lebih baik. ${ }^{14}$

\footnotetext{
${ }^{8}$ Hadari Nawawi, Administrasi Pendidikan, Jakarta: PT Toko Gunung Agung, 1997, hal. 103.

${ }^{9}$ Desi Eri Kusumaningrum, Raden Bambang Sumarsono, dan Imam Gunawan, "Problematika Pemberdayaan dan Pengembangan Sumber Daya Manusia di Sekolah Menengah Pertama Berbasis Pesantren", Ilmu Pendidikan: Jurnal Kajian Teori dan Praktik Kependidikan, Vol. 2 No. 2, 2017, Pp.141. DOI: http://dx.doi.org/10.17977/um027v2i22017p139

${ }^{10}$ Wiwik Maladerita, Dina Dahliana, Maistika Ratih \& Rifma, "Impelementasi Supervisi dalam Meningkatkan Proses Pembelajaran dan Pendidikan Karakter di Sekolah Dasar", Edukatif: Jurnal Ilmu Pendidikan, Vol. 1 No. 3 2019, Pp. 198-204. DOI: Https://Doi.Org/10.31004/Edukatif.V1i3.39

${ }^{11}$ Sri Nurhidah Abu, "Pembinaan Guru Oleh Kepala Sekolah dalam Pengelolaan Pembelajaran di Sekolah Dasar", Bahana Manajemen Pendidikan: Jurnal Administrasi Pendidikan, Vol. 2 No. 1 2014, Pp. 704. DOI: https://doi.org/10.24036/bmp.v2i1.3816

${ }^{12}$ Cut Suryani, "Implementasi Supervisi Pendidikan dalam Meningkatkan Proses Pembelajaran di MIN Sukadamai Kota Banda Aceh", Didaktika: Jurnal Ilmiah Didaktika, Vol. 16, No. 1, Pp. 23. DOI: http://dx.doi.org/10.22373/jid.v16i1.585

${ }^{13}$ Piet A Sahertian, Prinsip dan Tehnik Supervisi Pendidikan, Surabaya: Usaha Nasional, 1981, hal. 23.

${ }^{14}$ Cut Suryani, "Implementasi Supervisi Pendidikan dalam Meningkatkan Proses Pembelajaran di MIN Sukadamai Kota Banda Aceh", Didaktika: Jurnal Ilmiah Didaktika, Vol. 16, No. 1, Agustus, Pp. 27. DOI: Http://Dx.Doi.Org/10.22373/Jid.V16i1.585
} 
Metode dan teknik supervisi yang dapat dilakukan oleh pengawas diantaranya adalah metode-metode yang bersifat individual dan kelompok. Pada setiap metode supervisi tentunya terdapat kekuatan dan kelamahan. Ada bermacam-macam teknik supervisi dalam upaya pembinaan kemampuan guru. Dalam hal ini meliputi pertemuan staf, kunjungan supervisi, buletin profesional, perpustakaan profesional, laboratorium kurikulum, penilaian guru, demonstrasi pembelajaran, pengembangan kurikulum, pengambangan petunjuk pembelajaran, darmawisata, lokakarya, kunjungan antarkelas, bacaan profesional, dan survei masyarakat-sekolah. Sedangkan menurut Gwyn, teknik-teknik supervisi itu bisa dikelompokkan menjadi dua kelompok, yaitu. teknik supervisi individual, dan teknik supervisi kelompok.

Teknik supervisi individual di sini adalah pelaksanaan supervisi yang diberikan kepada guru tertentu yang mempunyai masalah khusus dan bersifat perorangan. Supervisor di sini hanya berhadapan dengan seorang guru yang dipandang memiliki persoalan tertentu. Teknik- teknik supervisi yang dikelompokkan sebagai teknik individual meliputi: kunjungan kelas, observasi kelas, pertemuan individual, kunjungan antarkelas, dan menilai diri sendiri. ${ }^{15}$ Teknik supervisi kelompok merupakan satu cara melaksanakan program supervisi yang ditujukan pada dua orang atau lebih sesuai dengan analisis kebutuhan, memiliki masalah atau kelemahan- kelemahan yang sama kemudian dikelompokkan atau dikumpulkan menjadi satu. Kemudian kepada mereka diberikan layanan supervisi sesuai dengan permasalahan yang di butuhkan

\section{Pengembangan Sumber Daya Manusia dengan Supervisi}

Di abad sekarang ini, yaitu era globalisasi dimana semuanya serba digital, akses informasi sangat cepat dan persaingan hidup semakin ketat, semua bangsa berusaha untuk meningkatkan sumber daya manusia. Pada dasarnya yang dimaksud sumber daya manusia adalah orang-orang yang melaksanakan suatu tugas untuk mencapai tujuan-tujuan tertentu. Dalam konteks lembaga pendidikan dibatasi dengan sebutan karyawan atau pegawai, oleh sebab itu, personel yang di lembaga pendidikan meliputi unsur tenaga pengajar dan tenaga kependidikan. Hanya manusia yang mempunyai sumber daya unggul dapat bersaing dan mempertahankan diri dari dampak persaingan global yang ketat. Di Indonesia konsep tujuan pendidikan adalah membentuk manusia seutuhnya yang tercermin dari iman dan taqwa, berkepribadian, cerdas, sehat serta bertanggung jawab. Untuk itu, maka pendidikan dalam prakteknya perlu menerapkan asas-asas yang sesuai. ${ }^{16}$ Termasuk sumber daya manusia dalam pendidikan karena masalah sumber daya manusia tersebut menjadi hal yang krusial dalam meningkatkan daya saing lulusan. Menurut Arifah Hidayati bahwa Madrasah Ibtidaiyah Muhamadiyah Juwiran pengembangan staf wajib hukumnya karena sebagai dorongan agar lebih baik lagi mengenai manajemn sumber daya manusia disamping itu pengembangan staf dilakukan untuk meningkatkan kualitas mutu Pendidikan di sekolah.

Guru merupakan penentu keberhasilan pendidikan melalui kinerjanya pada tataran institusional dan eksperiensial, sehingga upaya meningkatkan mutu pendidikan harus dimulai dari aspek "guru" dan tenaga kependidikan lainnya yang menyangkut kualitas keprofesionalannya maupun kesejahteraan dalam satu manajemen pendidikan yang

\footnotetext{
${ }^{15}$ Muhammad Hanief, "Menggagas Teknik Supervisi Klinik Sebagai Upaya Peningkatan Mutu Pembelajaran”, Jurnal Ilmiah Vicratina, Volume 10, No. 2 Nopember, Pp. 7.

${ }^{16}$ M. Ihsan Dacholfany, "Peranan Pengambilan Keputusan dalam Rangka Menciptakan Inovasi di Bidang Pendidikan”, Jurnal Dewantara, Vol. I , No .0 1 Januar I-Juni , Pp.25.
} 
professional. ${ }^{17}$ Mutu tenaga pendidik dan kependidikan menjadi hal yang utama untuk meningkatkan daya saing lulusan lembaga pendidikan, jadi tingginya mutu sumber daya manusia maka akan tinggi juga daya saing di lembaga pendidikan tersebut karena sumber daya manusia akan menciptakan lulusan-lulusan yang kompetitif dibandingkan lulusanlulusan di lembaga pendidikan lainnya. Melihat betapa pentingnya manejemen peningkatan mutu lulusan lembaga pendidikan, agar dapat dalam mengimplementasikannya tujuan ideal sebuah lembaga lembaga pendidikan dapat tercapai dan memuaskan masyarakat, stakeholder dan orang tua. Dengan konsep dan strategi yang baik maka terciptanya tenaga pendidikan yang berkualitas dan tentunya juga akan menghasilkan SDM/lulusan yg berkualitas. ${ }^{18}$

Ada dua metafora untuk menggambarkan pentingnya pengembangan sumber daya guru. Salah satu upaya pengembangan sumber daya guru adalah dengan melakukan pelatihan dan pengembangan. Pelatihan dan pengembangan merupakan kegiatan yang bermaksud memperbaiki dan mengembangkan sikap, perilaku, keterampilan dan pengetahuaan para guru sesuai dengan kenginan lembaga pendidikannya baik bagi guru untuk guru yang baru dan guru yang lama. ${ }^{19}$ Pertama, jabatan guru diumpamakan dengan sumber air. Kedua, jabatan guru diumpamakan dengan sebatang pohon buah-buahan.

Kinerja guru adalah hasil kerja yang dapat dicapai oleh seorang guru dilembaga pendidikan sesuai dengan tugas dan tanggung jawabnya dalam mencapai tujuan pendidikan". Kinerja guru menyangkut seluruh aktivitas yang ditunjukkan oleh tenaga pengajar dalam tanggung jawabnya sebagai seorang yang mengemban suatu amanat dan tanggung jawab untuk mendidik, mengajar, membimbing, mengarahkan, dan memandu peserta didik dalam rangka menggiring perkembangan peserta didik ke arah kedewasaan mental-spiritual maupun fisik- biologis. Dalam suatu organisasi atau setiap individu memiliki karakter yang berbeda, maka Kepala Sekolah harus bisa memahami perbedaan cara kerja guru dan faktor-faktor yang mempengaruhi kinerja guru, faktor tersebut terdapat dari dalam maupun dari luar seorang guru yang akan mempengaruhi kinerjanya. ${ }^{20}$

Faktor dari dalam meliputi pendidikan dari guru, pengalaman, keterampilan, motivasi serta kepribadian dari guru tersebut, sedangkan faktor dari luar meliputi kondisi di lingkungan kerja. Kepemimpinan kepala sekolah merupakan salah satu komponen pendidikan yang paling berperan dalam peningkatan kualitas pendidikan.sangat erat hubungannya antara mutu kepala sekolah dengan berbagai aspek kepala sekolah, iklim budaya sekolah. Dengan demikian kepala sekolah bertanggung jawab secara langsung terhadap proses pembelajaran di sekolah, penyelenggaraan, administrasi dan sebagainya. Kepemimpinan Kepala sekolah sebagai penanggung jawab semua komponen yang berkaitan dengan sekolah, mengawasi dan mengkoordinasi sekaligus sebagai penggerak semangat para guru, staf, dan siswa, dalam pencapaian tujuan yang telah di tetapkan bersama-sama. ${ }^{21}$ Maka dari itu sangat penting bagi

\footnotetext{
${ }^{17}$ Piet A Sahertian, Konsep-Konsep dan Teknik Supervisi Pendidikan dalam Rangka Pengembangan Sumber Daya Manusia, Jakarta: Rineka Cipta, 2000, hal. 20.

${ }^{18}$ Tim Dosen Administrasi Pendidikan UPI, Manajemen Pendidikan, Bandung: Alfabeta, 2011, hlm. 302.

${ }^{19}$ Candra Wijaya, Achyar Zein, dan Ali Ahmad Rapi Tanjung, "Strategi Manajemen Kepala Madrasah dalam Mengembangkan Sumber Daya Guru di MTs Persiapan Negeri Hadundung Kecamatan Kota Pinang Kabupaten Labuhanbatu Selatan", Edu Riligia: Jurnal Ilmu Pendidikan Islam dan Keagamaan, http://dx.doi.org/10.47006/er.v4i1.8111 Vol. 4 No. 1 Januari- Maret, pp. 93.

${ }^{20}$ Presti Putri Riwana, 2019. "Pengaruh Pelaksanaan Supervisi Pendidikan Oleh Kepala Sekolah Terhadap Kinerja Guru di Sekolah”. Jurnal Supervisi Pendidikan, pp. 1-4, http://Doi:10.31227/osf.io/hc4k8

${ }^{21}$ Sumidjo Wahjo, Kepemimpinan Kepala Sekolah, (Jakarta: Raja Grafindo Persada, 2003), hal. 8.
} 
kepala sekolah untuk dapat memahami kondisi dan karakter sehingga ia dapat mengetahui bagaimana cara meningkatkan kinerja guru tersebut dan dengan demikian guru dan kepala sekolah dapat berkerja sama dengan baik dan membangun iklim kerja yang kondusif dan efektif sehigga kinerja guru dapat kondusif. Kepemimpinan kepala sekolah merupakan salah satu faktor yang dapat mendorong sekolah untuk mewujudkan visi, misi, tujuan, dan sasaran sekolah melalui program-program yang dilaksanakan secara terencana dan bertahap.

Dalam pendidikan, supervisi merupakan sebagai suatu hal untuk membantu agar kualitas dari mengajar dan pembelajaran dapat berjalan dengan baik, supervisi ini diberikan dari atasan kepada bawahan yang tujuannya untuk meningkatkan kualitas kerja. Kepala sekolah merupakan wujud supervisor yang mana ia akan mengawasai dan memberi binaan terhadap semua kinerja guru di sekolah tersebut, dan yang mana kepala sekolah tersebur terlenih dahulu harus memahami setiap tugas dan kedudukan para staf dan karyawannya. Dan kepala sekolah harus mengawasi semua kegiatan yang dilakukan oleh bawahannya tersebut sehingga pengawasan dan pembinaan tersebut berjalan dengan baik dan tidak membingungkan.

\section{Bentuk-Bentuk Pengembangan Staf Pendidik Di Madrasah Ibtidaiyah Muhammadiyyah Juwiran Klaten}

Tugas utama organisasi profesi bertalian dengan pengembangan profesi pendidik adalah mengkoordinasi kesempatan yang ada untuk meningkatkan profesi, menilai tingkat profesionalisme pendidikan, mengawasi pelaksanaan pendidikan dan perilaku pendidikan sebagai seorang profesional dan menjatuhkan sanksi terhadap mereka yang melanggar kode etik profesi Pendidikan. Setiap program kerja organisasi profesi keguruan disusun dengan menggunakan alur kerja sebagai berikut: pertama di adakan kajian secara teoritis dan empiris yang mantap untuk mendiskripsikan kebutuhan pengembangan diri serta profesionalitas para guru, baik yang bersifat kuratif (remidial; pembenahan atau perbaikan), preservatif (membina serta mempertahankan eksistensi dan kecakapan kerja yanbg terstandar), maupun yang bersifat preventif (antisipatif; menjawab tantangan yang diduga akan muncul sebagai akibat perkembangan iptek dan kebutuhan masyarakat yang semakin modern) kedua, daftar kebutuhan pengembngan diri guru serta profesionalitasnya, yang telah dipolakan dengan mempertimbangkan prioritas setiap satuan kebutuhan (hasil kerja tahap pertama), perlu dimantapkan dengan meminta konfirmasi dan atau persetujuan dari para ahli di bidang keguruan dan para guru yang mengenali dengan baik tuntutan profesinya serta yang berhasil dalam kerjanya. Penyelesaian tahap kedua ini umumnya ditempuh dengan menyelenggarakan seminar, lokakarya dan konsultasi. Ketiga, perumusan program kerja secara definiif, penggandaan penyebarluasan, dan pengarsipannya. ${ }^{22}$

Adapun bentuk-bentuk kegiatan pengembangan staf di madrasyah Ibdidaiyah Muhammadiyah Juwiran Klaten diantaranya adalah; Peningkatan melalui penataran; yaitu penataran yang diselenggarakan oleh Depdikbud; Peningkatan profesi melalui belajar sendiri; Peningkatan profesi melalui media massa; Peningkatan profesi keguruan melalui organisasi profesi. Mengingat peranan stategis staf pendidik dalam setiap upaya peningkatan mutu

${ }^{22}$ A. Samana, Profesionalisme Keguruan: Kompetensi dan Pengembangannya, (Yogyakarta: Kanisius, 1994), hal. 101. 
relevansi dan efesiensi pendidikan, maka pengembangan profesional guru merupakan kebutuhan.

\section{KESIMPULAN}

Supervisi adalah segala bantuan dari para pemimpin sekolah, yang mempunyai tujuan untuk mengembangkan kepemimpinan guru-guru dan personel sekolah dalam mencapai tujuan-tujuan pendidikan. Fungsi supervisi dalam pendidikan bukan hanya sekadar mengontrol apakah kegiatan yang telah dilaksanakan sesuai dengan rencana atau program yang telah digariskan, tetapi supervisi juga bertujuan mengembangkan situasi belajar dan mengajar yang lebih baik sehingga tercapai tujuan akhir dari pendidikan yaitu pembentukan pribadi anak secara maksimal dan juga meningkatkan mutu Pendidikan di sekolah. Salah satu cara mengembangkan sumber daya manusia dengan supervisi yaitu dengan meningkatkan mutu pendidikan yang harus dimulai dari aspek guru dan tenaga kependidikan lainnya yang menyangkut kualitas keprofesionalannya maupun kesejahteraan dalam satu manajemen pendidikan yang professional.

\section{DAFTAR PUSTAKA}

Abu, Sri Nurhidah. "Pembinaan Guru Oleh Kepala Sekolah Dalam Pengelolaan Pembelajaran Di Sekolah Dasar", Bahana Manajemen Pendidikan: Jurnal Administrasi Pendidikan, Vol. 2 No. 1 2014, Pp. 704. DOI: https://doi.org/10.24036/bmp.v2i1.3816

Almasri, M. Nazar. "Manajemen Sumber Daya Manusia: Imlementasi Dalam Pendidikan Islam", Kutubkhanah: Jurnal Penelitian Sosial Keagamaan, Vol.19, No.2 2016, Pp. 134.

Aziz, Amrullah. "Pendidik Profesional yang Berjiwa Islami”, Pancawahana: Jurnal Studi Islam, Vol. 10, No. 1 2015, Pp. 57.

Dacholfany, M. Ihsan. "Peranan Pengambilan Keputusan dalam Rangka Menciptakan Inovasi di Bidang Pendidikan”, Jurnal Dewantara, Vol I, No .0 1 Januar I-Juni , Pp.25.

Eri Kusumaningrum Desi, Raden Bambang Sumarsono, dan Imam Gunawan, "Problematika Pemberdayaan Dan Pengembangan Sumber Daya Manusia di Sekolah Menengah Pertama Berbasis Pesantren", Ilmu Pendidikan: Jurnal Kajian Teori dan Praktik Kependidikan, Vol. 2 No. 2, 2017, Pp.141. DOI:http://dx.doi.org/ 10.17977/ $\underline{\mathrm{um} 027 \mathrm{v} 2 \mathrm{i} 22017 \mathrm{p} 139}$

Fitrah, Muh. "Peran Kepala Sekolah dalam Meningkatkan Mutu Pendidikan", Jurnal Penjaminan Mutu, Vol. 3 No 1 2017, Pp 34. DOI: http://dx.doi.org/10.25078/ jpm.v3i1.90

Hamid, Abdul. "Guru Profesional", Al Falah: Jurnal Ilmiah Keislaman dan Kemasyarakatan, Vol. XVII No. 32, 2017, Pp. 278. DOI: https://doi.org/10.47732/alfalahjikk.v17i2.26

Hanief, Muhammad. "Menggagas Teknik Supervisi Klinik Sebagai Upaya Peningkatan Mutu Pembelajaran”, Jurnal Ilmiah Vicratina, Volume 10, No. 2 Nopember, Pp. 7.

Maladerita, Wiwik; Dahliana, Dina; Ratih, Maistika \& Rifma, "Implementasi Supervisi dalam Meningkatkan Proses Pembelajaran dan Pendidikan Karakter di Sekolah 
Dasar", Edukatif: Jurnal Ilmu Pendidikan, Vol. 1 No. 3 2019, Pp. 198-204. DOI: Https://Doi.Org/10.31004/Edukatif.V1i3.39

Musfiqon. Panduan Lengkap Metodologi Penelitian Pendidikan. Jakarta: PT. Prestasi Pustakaraya. 2015.

Nasution, Lukman; Sagala, S. \& Daryanto, Eka. "Kebijakan Kepala Sekolah Sebagai Supervisor dalam Pengembangan Staf dan Kurikulum di SMA Negeri 2 Medan". Educandu M: Jurnal Manajemen Pendidikan, Vol.11 No.2 2018, Pp 1.

Nawawi, Hadari. Administrasi Pendidikan, Jakarta: PT Toko Gunung Agung, 1997.

Riwana, Presti Putri. "Pengaruh Pelaksanaan Supervisi Pendidikan Oleh Kepala Sekolah Terhadap Kinerja Guru di Sekolah”. Jurnal Supervisi Pendidikan, 2019, pp. 1-4, http://Doi:10.31227/osf.io/hc4k8

Sahertian, Piet A. Konsep-Konsep dan Teknik Supervisi Pendidikan dalam Rangka Pengembangan Sumber Daya Manusia, Jakarta: Rineka Cipta, 2000.

Sahertian, Piet A. Prinsip dan Tehnik Supervisi Pendidikan, Surabaya: Usaha Nasional, 1981.

Samana, A. Profesionalisme Keguruan: Kompetensi dan Pengembangannya. Yogyakarta: Kanisius, 1994.

Subandi, Ahmad. "Supervisi Pendidikan Untuk Pengembangan Profesionalitas Guru Berkelanjutan”, Pedagogi: Jurnal Ilmiah Ilmu Pendidikan, Vol. XIII No.2, 2013, Pp. 2.

Suryani, Cut. "Implementasi Supervisi Pendidikan dalam Meningkatkan Proses Pembelajaran di MIN Sukadamai Kota Banda Aceh”, Didaktika: Jurnal Ilmiah Didaktika, Vol. 16, No. 1, Pp. 23. DOI: http://dx.doi.org/10.22373/jid.v16i1.585

Tim Dosen Administrasi Pendidikan UPI, Manajemen Pendidikan. Bandung: Alfabeta. 2011

Wahjo, Sumidjo. Kepemimpinan Kepala Sekolah. Jakarta: Raja Grafindo Persada, 2003.

Wijaya, Candra; Achyar Zein; dan Ali Ahmad Rapi Tanjung, "Strategi Manajemen Kepala Madrasah dalam Mengembangkan Sumber Daya Guru di MTs Persiapan Negeri Hadundung Kecamatan Kota Pinang Kabupaten Labuhanbatu Selatan”, Edu Riligia: Jurnal Ilmu Pendidikan Islam dan Keagamaan, http://dx.doi.org/10.47006/ er.v4i1.8111 Vol. 4 No. 1 Januari- Maret, pp. 93. 